A theoretical framework and research agenda for studying team attributions in sport

\title{
REVISION
}

Date of submission: $3^{\text {rd }}$ October 2011

Date of revised submission $29^{\text {th }}$ November 2011 


\begin{abstract}
The attributions made for group outcomes have attracted a great deal of interest in recent years. In this article we bring together much of the current research on attribution theory in sport and outline a new conceptual framework and research agenda for investigating the attributions of team members. The proposed framework draws on multiple conceptual approaches including models of attribution, group dynamics and stress responses to provide a detailed hypothetical description of athletes' physiological, cognitive and affective responses to group competition. In describing this model we outline important antecedents of team attributions before hypothesising how attributions can impact hormonal and cardiovascular responses of athletes, together with cognitive (goals, choices, expectations), affective (selfesteem, emotions), and behavioural (approach-avoidance actions) responses of groups and group members. We conclude by outlining important methodological considerations and implications for structured context specific attribution-based interventions.
\end{abstract}

Keywords: approach-avoidance motivation, group dynamics, neuroendocrinology 


\section{A theoretical framework and research agenda for studying team attributions in sport}

Long term success in sport is partly a function of how people interpret and evaluate competition success and failure. The explanations people assign to outcomes are termed attributions. The attributions people make for sporting outcomes can be a powerful source of motivation, influencing emotions, decisions, expectations and behaviours (for reviews see Försterling, 2001; Malle, 2004). This literature review is concerned with the attributions made for competition outcomes by team members. Following a précis of the current literature, we describe various situational and dispositional characteristics of groups and group members potentially responsible for shaping the attributions made for team outcomes. We then go on to describe how such attributions are likely to influence future team performance through the cognitive, affective and physiological states of team members. Specifically, using recent sport specific conceptualisations (Rees, Ingledew, \& Hardy, 2005) we draw on concepts of achievement motivation (Weiner, 1985, 2010), models of hormonal responses to competition (Archer, 2006; Salvador, 2005), and the group dynamics literature (e.g. Tajfel \& Turner, 1986), to formulate a conceptual framework and research agenda for investigating team attributions in sport.

\section{Overview of team attributions in sport}

Team attributions are the explanations provided for group behaviour. The terms team attributions and team-referent attributions are often used in research. Team-referent attributions refer to individuals' perceptions of the causes of group performance, whereas team attributions are the aggregated attributions of each team member. Thus, attributions are sometimes described as a perception held by an athlete and sometimes as a shared belief held by a collective. Since inanimate social structures cannot experience emotions or have beliefs in the same way that people can, attributions should always be thought of as the opinions of the individual group members, but shared experiences and social interaction often cause 
group members to think and respond in similar ways (see Myers \& Feltz, 2007 for a good discussion of shared perceptions in groups). In most cases, the relationships described here apply to both individual team members and to the average responses of the collective. Consequently, this distinction is largely ignored throughout and the terms team attributions and team-referent attributions are used interchangeably. However, shared perceptions have important measurement and practical implications that are given further consideration towards the end of this review.

A useful approach to researching and understanding team attributions is to classify causes along dimensions that reflect a particular intrinsic property. Traditionally, researchers have explored the degree to which causes are perceived as residing within the team or outside the team (locus of causality) or explored the degree to which team members take personal responsibility for group outcomes or place responsibility firmly with teammates. A number of outcome biases have been demonstrated using these classification schemes, including the team-serving attribution bias (the tendency to attribute positive outcomes to factors within the team and negative outcomes to factors outside the team), the egocentric bias (the tendency for group members to take more personal responsibility for group outcomes than others give to them), the self-serving bias (the tendency to identify oneself as more responsible for positive group outcomes than negative group outcomes), the group attribution error (the tendency to identify team characteristics as responsible for other group's outcomes), and the false consensus effect (the tendency for group members to overestimate the degree of agreement others have with them). Currently, only the team-serving attribution bias has received good support in sport settings (Allen, in press).

More recently, building on popular approaches to person-centred attribution research (Abramson, Seligman, \& Teasdale, 1978; Weiner, 1985), team attributions have been categorised along a greater number of dimensions to provide researchers with further insight 
into the intrinsic meaning of the attribution made. Other attribution dimensions assessed in research include controllability (the degree to which the cause is perceived as under the control of the team), and three generalisability dimensions of stability (the degree to which the cause is perceived to generalise across time), globality (the degree to which the cause is perceived to generalise across situations) and universality (the degree to which the cause is perceived to generalise across teams). These four dimensions have been outlined as particularly relevant for sport outcomes (Rees et al., 2005) and form the basis of our conceptual model.

\section{The need for a new theory}

Our motivation for developing this framework stems from a number of concerns with using currently available models. First, many sport based studies have tested, and not supported, predictions outlined within more general frameworks of causal attribution. In particular, there is much variability in studies exploring the relationship between attribution dimensions and emotional responses of athletes (Biddle, Hanrahan, \& Sellars, 2001). Second, various studies describing physiological changes of sport performers suggest that attributions should impact hormonal and cardiovascular responses to success and failure (Salvador, 2005; Salvador \& Costa, 2009). However, the measurement of physiological consequences of attributions are noticeably absent from all attribution theories. Third, individual differences and moderators of the outcome - attribution relationship are often given scant attention in theories describing the consequences of attributions, leaving little breadth for multifaceted interventions. Fourth, recent sport attribution research has used an expanded conceptualisation of generalisability dimensions (Coffee \& Rees, 2008a; Rees et al., 2005) that may be particularly useful when considering the attributions made for group outcomes. Finally, empirical research demonstrates advantages for moving beyond hypothesising and exploring main effects of attributions to specifying and testing interactive 
effects of attribution dimensions (Coffee, 2010). For these reasons, and because attributions are likely to have a meaningful effect on future team performance, we believe an updated framework of causal attribution is warranted.

\section{Overview}

In proposing this conceptual model, we amalgamate and extend a number of conceptual approaches to attribution including early models describing the antecedents of attributions (Heider, 1958; Jones \& Davis, 1965; Kelley, 1967). Building on these models, we outline various factors that should impact meaningfully on the attributions made by team members. These include dispositional qualities of the group and group members (including personalities, levels of experience, and relationships among teammates) and characteristics of the particular event in question (including expectations for the competition, the importance of competition, and critical incidents within competition). We propose these factors as largely responsible for shaping the attributions made by team members.

There are various ways researchers can choose to categorise attributions and our model focuses on four dimensions relevant for sport outcomes: controllability and the three generalisability dimensions of stability, globality and universality (Rees et al., 2005). Our decision to move away from traditional (locus of causality) classifications was based on the tendency for most team members to take collective responsibility for both team success and team failure (Allen, 2009) and the relatively large overlap between where a cause lies (locus of causality) and by whom it is controlled (Rees et al., 2005). Rees and colleagues (2005) have suggested that a more beneficial approach to studying attributions is to focus upon the controllability of causes, together with adopting a broader conceptual approach to classifying the generalisability of attributions (in addition to stability, exploring the globality and universality of attributions). This conceptualisation enables researchers to explore how perceptions of controllability generalise across time (stability), situations (globality) and 
teams (universality), through going beyond the testing of main effects of attributions to exploring interactive effects of controllability and generalisability dimensions (Coffee \& Rees, 2008a).

Our conceptual model draws on concepts of achievement motivation (Weiner, 1985, 2010) and stress reactivity (Archer, 2006; Salvador, 2005; Salvador \& Costa, 2009) to understand the mechanisms through which attributions can influence behaviour predispositions. We propose that team attributions, as classified along the dimensions of controllability (controllable to uncontrollable), stability (stable to unstable), globality (specific to global) and universality (local to universal), can influence physiological responses of team members, including testosterone, cortisol, heart rate, blood pressure, and immune function; affective responses of team members, including pride, self-esteem, frustration, anger, dejection, and happiness; cognitive responses of team members, including expectations, collective efficacy, team goals, and decisions; and group/member behaviour patterns, including approach-avoidance actions, quality of training, and subsequent team performance. The full model is depicted in Figure 1. What follows is a detailed description of the attribution model with a particular emphasis on the dimensions (and their interactions) involved in hypothesised relationships.

*** INSERT FIGURE 1 HERE ***

\section{Attribution Antecedents}

The first complete frameworks of attribution were concerned largely with the information people use to make causal inferences (Heider, 1958; Jones \& Davis, 1965; Kelley, 1967). Although these theories differ in many respects, all contend that explanations are derived from aspects of the current situation and dispositional qualities of the individual (e.g. attitudes, experiences). Here we continue this simple taxonomy and describe how 
dispositional qualities of the team and aspects of the current competition contribute to the attributions made by team members.

\section{Individual/group differences}

Enduring characteristics of athletes and teams can be expected to have a meaningful effect on the way outcomes are perceived by athletes. Based on our reading of the current literature we have reason to believe that three interlinked factors can account for many of the observed relationships and should act as genuine precursors to athlete attributions. These are: personality, experience, and intragroup relationships.

Several research investigations have demonstrated that attributions are related to specific components of personality including trait anxiety (Anshel \& Brinthaupt, 2006), trait self-handicapping (Greenlees, Jones, Holder, \& Thelwell, 2006), perfectionism (Stoeber \& Becker, 2008), hardiness (Hull, van Treuren, \& Propson, 1988) and mental toughness (Davis \& Zaichkowsky, 1998). These research findings may be demonstrating a relationship between attributions and personality that could be represented more generally through two global personality dimensions: neuroticism (the degree to which individuals are prone to emotional instability) and conscientiousness (the degree to which individuals are prone to organisation and goal directed behaviour). Conscientious and emotionally stable athletes (often characteristics of leaders) should be less inclined to make self-serving attributions (e.g. team-serving bias) since an accurate attribution can help direct resources towards goals (characteristics of a conscientious personality) and an inaccurate attribution can help protect or enhance personal self-esteem (characteristics of an emotionally unstable personality). If conscientious and emotionally stable athletes make fewer team-serving judgements we can expect such athletes to show a greater use of controllable, unstable, specific, and local attributions following team success, and a greater use of controllable, stable, global, and universal attributions following team failure. 
Personality differences across sport populations can also help explain why men tend to show more self-serving and team-serving attributions than women (Green \& Holeman, 2004; Hendy \& Boyer, 1993; Pedersen \& Manning, 2004) and why members of interdependent sport teams show more team-serving attributions than members of coactive sport teams (Zaccaro, Peterson, \& Walker, 1987). That is, women are typically more conscientious, compassionate, and emotionally unstable than men (Allen, Greenlees, \& Jones, 2011a; Schmitt, Realo, Voracek, \& Allik, 2008) and athletes in low interdependent sports tend to be more introverted, conscientious, and emotionally stable than athletes in high interdependent sports (cf. Allen et al., 2011a; Eagleton, McKelvie, \& deMan, 2007; Rhea \& Martin, 2010). If conscientious and emotionally stable athletes make fewer team-serving attributions this could explain why attributions appear more biased in competitions involving men or high interdependence.

The attributions made for competition outcomes have also been correlated with athlete characteristics such as skill level (Grove \& Prapavessis 1995), ability (Roesch \& Amirkhan, 1997), competition level (González-Boto, Molinero, Martinez, \& Marquez, 2006), age (Hamilton \& Jordan, 2000; White, 1993), player seniority (Kerr \& Beh, 1995) and time of season (Kerr \& Beh, 1995; Lau, 1984). In each case, we would argue that all measures are providing non-explicit indices of athletic experience. That is, more experienced athletes are generally older, of higher ability, competing at a higher level, and considered more senior by their peers. The general finding of these studies is that athletes with less experience (i.e. lower ability, lower achievement, less seniority, lower competition level, early season and younger athletes) show a greater use of self-serving or team-serving attributions than athletes with greater experience.

Athletic experience can be measured explicitly in one of two ways: (1) the total experience a particular athlete has had in the sport, and (2) the experience they have had with 
their current team. Both factors should influence team attributions. Simply put, with greater experience people become more capable of correctly identifying the causes of their team's successes and failures. Thus, athletes with less experience are more likely to make inaccurate or self-serving attributions (controllable, stable, global and local causes following team success; and controllable, unstable, specific and universal causes following team failure) than athletes with greater experience. Generally it will be total sport experience rather than current team experience that influences team attributions. However, once a certain level of knowledge about a sport is acquired (e.g. after completing at least one full season in the sport) current team experience becomes the critical consideration. That is, most athletes will have developed a good knowledge of the sport and the general causes of both good and poor performance (what Kelley, 1967, terms causal schemata - knowledge about how certain types of events require specific causes). Therefore, an understanding of the current team, something akin to team attitudes (derived from experiences), is the critical factor influencing attributions. Thus, newly formed teams (or teams with many new players) will show different attributions to more established teams, and also, teams with more experienced athletes will show different attributions to teams with less experienced athletes.

Alongside personality and athletic experience, relationships among teammates and factors that affect those relationships (e.g. ingroup deviance) are likely to have a meaningful effect on the attributions made by team members. Indeed, research in team sport has shown an important association between levels of team cohesion and the attributions made by team members (Bird, Foster, \& Maruyama, 1980; Shapcott, Carron, Greenlees, \& El Hakim, 2010; Taylor \& Tyler, 1986; Taylor, Doria, \& Tyler, 1983). This relationship is likely a function of greater team identification in highly cohesive groups. In general, when relationships among teammates are strong athletes will experience greater identification with their team and consequently are more concerned with protecting or enhancing the status of that team (Tajfel 
$\&$ Turner, 1986). Therefore, as social cohesion increases negative outcomes are perceived as more threatening to self-esteem and attributions become increasingly self-serving (e.g. team serving bias). This is consistent with research in non-athletic domains showing that threats to self-esteem cause people to bias their attributions only when team identification is relatively high (Smurda, Wittig, \& Gokalp, 2006). We would expect members of highly cohesive teams to show a greater use of attributions that enhance or protect the status of their team (controllable, stable, global and local attributions for team victory; controllable, unstable, specific and universal attributions for team defeat) and members of low cohesive teams to show a greater use of attributions that protect the self at the expense of the team. However, the degree to which negative outcomes are perceived as threatening to self-esteem is heavily influenced by the particular match or competition in question. That is, situations such as cup finals or local derby's should result in a greater use of team-serving attributions than general league matches or pre-season warm-up games. It is to these situational factors this review now turns.

\section{Event Information}

Dispositional characteristics of athletes and groups can account for much of the variability in team attributions, and these will generally predict how team members respond consistently across sport competitions (team attributional style). However, in most cases attributions are generated relative to the information received from aspects of the current competition. Although critical incidents occurring during competition will no doubt have a strong influence on the attributions made by team members, it should be possible to identify beforehand how athletes are likely to respond to outcomes based on general characteristics of the event in question (e.g. the importance of the competition and expectations for that competition). 
An interesting study of student athletes' throwing performance showed that both men and women are more likely to attribute defeat to characteristics of their opponents when competing against someone of the opposite sex than when competing against someone of the same sex (Croxton, Chiacchia, \& Wagner, 1987). This effect could have emerged because losing to a member of the opposite sex is more damaging to personal self-esteem (possibly a characteristic of sex-typed sports). On the other hand, attributions may have differed because of the expectations people form about opponents before competition. Indeed, people make judgements and form expectations about opposing teams even in the absence of direct observation (e.g. comparing league positions of own team against forthcoming opponents). Following a loss to a team perceived as weaker will likely result in attributions to atypical or unusual circumstances that are unlikely to be present in future competitions. Thus, attributions for team defeat should be more uncontrollable, unstable, specific, and local against opponents perceived as weaker. In a similar manner, victory against opponents perceived as stronger is also likely to arouse suspicions of atypical or unusual circumstances resulting in a greater use of uncontrollable, unstable, specific, and local attributions.

In most cases it is expectations against opponents, rather than specific characteristics of those opponents, that are responsible for shaping attributions. Indeed, when team members go into competitions confident of team success they tend to report more team controllable and stable attributions than when they go into competitions with little confidence of team success (Chow \& Feltz, 2008; Greenlees, Graydon, \& Maynard, 2000). The influence of prior expectations on athlete attributions has also been tested experimentally (Belciug, 1992; Lau \& Russell, 1980). These studies found that when expectations are high, and confirmed, attributions are more stable than when expectations are high and disconfirmed. Also, when expectations are low, both confirmation and disconfirmation of those expectations are associated with a greater use of variable (unstable) attributions. The 
finding that expectations of failure, coupled with actual success, were associated with more unstable attributions is consistent with hypotheses outlined above. The finding that expectations of success, coupled with actual failure, were associated with more unstable attributions is also consistent with these hypotheses. In such (unanticipated) circumstances, we can also predict that team members will show more uncontrollable, specific and local attributions as hypothesised above.

Alongside athlete expectations, the importance attached to competition also has an important role in forming team attributions. This is because important outcomes are more threatening to athlete self-esteem than are unimportant outcomes. That is, if the competition being played is not viewed as an important part of the individual's self-concept (i.e. it is a meaningless encounter) then there is little reason to bias attributions to protect self-esteem (Greenlees, Lane, Thelwell, Holder, \& Hobson, 2005). Research in team sport has shown some support this notion with female athletes reporting a greater use of stable attributions for team success than for team failure only when the competition is perceived as particularly important (Greenlees et al., 2007). The importance attached to competition can also explain why attributions appear to change with time. Over time, competitions become less important to athletes, and consequently less threatening to athlete self-esteem (Allen, 2010). As a consequence, the inclination to bias attributions dissipates and is replaced by a desire to have greater control over the outcome (Allen, 2010). This is because an attribution of control allows for personal and/or team improvement.

\section{Summary}

To develop structured attribution-based interventions it is important to have an understanding of those factors that contribute to the attributions made by team members. We believe those outlined here, although not an exhaustive list, can account for much of the variability in team attributions and provide opportunities for developing context specific 
structured interventions. The interaction between these factors may also be important as demonstrated through attribution research exploring interactions between gender and ability (Hanrahan \& Cerin, 2009), gender and age (Bird \& Williams, 1980; Mezulis, Abramson, Hyde, \& Hankin, 2004) and gender and competition importance (Greenlees et al., 2007). However, we recognise that attributions arise not only from dispositions and characteristics of the competition but also from critical incidents occurring during competition and people's memory of those incidents (Allen, Jones, \& Sheffield, 2010). These are less easy to identify and control for, and perhaps where sport psychology consultants will need to be more intuitive in delivering interventions on a group-by-group basis.

One important factor that has not been outlined here, but may overshadow many of those presented, are social factors. Team members often reflect on the causes of group outcomes in a social environment and consequently attributions are influenced by the verbal and non-verbal information received from teammates, coaches and others (Moscovici \& Hewstone, 1983). Such social exchanges can often be a more powerful source of information than the information derived from personal observations. However, the root sources of conveyed social information derive from the same dispositional and situational factors outlined in Figure 1. Thus, team members will display some level of consensus in their attributions and some team members will have a greater influence on team attributions than others. For instance, those individuals with strong personalities (e.g. extraverted, conscientious athletes) are likely to convey more information to others (contributing more to team consensus) and personality characteristics might also predict the degree to which individuals are susceptible to suggestion (opinions of other members) or willing to test group opinion (groupthink). Consensus in team attributions has implications for both measurement and attribution consequences, and is given further consideration towards the end of this review. It is to the consequences of team attributions this review now turns. 


\section{Attribution Consequences}

Attributions "are everyday occurrences that determine much of our understanding of and reaction to our surroundings" (Heider, 1958, p. 16). In team settings, athletes report a range of attributions (Allen, 2009) and several studies have demonstrated that such attributions are important for cognitive and affective states of team members (e.g. Allen, Jones, \& Sheffield, 2009b; Dithurbide, Sullivan, \& Chow, 2009). To understand how team attributions influence behaviour patterns we recommend that researchers focus on four underlying dimensions: controllability, and three generalisability dimensions of stability, globality and universality. This conceptualisation enables researchers to explore how perceptions of controllability generalise across time (stability), situations (globality), and teams (universality), through going beyond the testing of main effects of attributions to exploring interactive effects of controllability and generalisability dimensions (Coffee \& Rees, 2008a; Rees et al., 2005). Building upon the results of recent research (see Coffee, 2010 , for a review), our main hypothesis is that main effects of generalisability dimensions have a greater role following team success; following team failure, main effects of controllability are important but they are conditioned by interactive effects for controllability and generalisability dimensions. In other words, perceptions of uncontrollability are particularly problematic when causes are also considered to generalise across time and/or situations and/or are perceived as unique to the team. In this next section we outline more specifically how team attributions can influence the physiological, affective, cognitive, and behavioural responses of group members.

\section{Physiological Consequences}

The relationship between sport outcomes and neuroendocrine activation has been researched extensively in recent years (for reviews see Salvador, 2005; Salvador \& Costa, 2009). Several early studies observed that winning causes an increase in testosterone and 
cortisol levels, and losing causes a decrease in testosterone levels (Elias, 1981; Mazur \& Lamb, 1980). However, such findings were not consistently replicated in subsequent research. Although winning seems to elicit an increase in testosterone (Carré \& Putnam, 2010; Fry, Schilling, Fleck, \& Kraemer, 2011; Oliveira, Gouveia, \& Oliveira, 2009), losing can also elicit increases in testosterone (van der Meij, Buunk, Almela, \& Salvador, 2010) and cortisol (Bateup, Booth, Shirtcliff, \& Granger, 2002), and a number of studies have shown no change in testosterone or cortisol levels following either victory or defeat (González-Bono, Salvador, Serrano, \& Ricarte, 1999; Passelergue \& Lac, 1999). Taken as a whole, results have not supported a clear pattern between competition outcome and hormonal responses of athletes. This has led many researchers to explore other potential causes and studies have since demonstrated that it is the perception of the situation that is largely responsible for neuroendocrine activation (van der Meij et al., 2010; Suay et al., 1999). Thus, hormonal responses to competition are not a direct consequence of winning and losing but rather are mediated by complex psychological processes (Salvador, 2005).

The attributions made for success and failure are among those factors proposed to influence hormonal responses of athletes (Salvador, 2005). Indeed, research has shown that attributions to personal effort (often considered controllable and unstable) are associated with high testosterone levels (Serrano, Salvador, González-Bono, Sanchis, \& Suay, 2000) and that testosterone levels differ between winners and losers only when attributions are made to personal ability (often considered uncontrollable and stable) (van Anders \& Watson, 2007). Two studies have also shown that testosterone levels are related to the attributions made for group outcomes (González-Bono et al., 1999; González-Bono, Salvador, Ricarte, Serrano, \& Arnedo, 2000). Specifically, findings showed that attributions to factors outside the team (usually considered uncontrollable) were negatively associated with testosterone levels in winning teams and positively associated with testosterone levels in losing teams. Although 
cortisol responses have not been explored in relation to team attributions, a separate body of literature has looked at cortisol reactivity in controllable and uncontrollable situations (see Blascovich, Vanman, Mendes, \& Dickerson, 2011). In particular, a meta-analysis of 208 studies demonstrated that uncontrollable stressors are associated with significantly larger cortisol responses (effect size $d=.52$ vs. $d=.16$ ) than controllable stressors (Dickerson $\&$ Kemeny, 2004).

Alongside hormonal responses, competition outcomes can also elicit a cardiovascular response (Ricarte, Salvador, Costa, Torres, \& Subirats, 2001). In an unpublished study by Salvador, Costa, and González-Bono (cited in Salvador \& Costa, 2009) participants were persuaded that the outcome of a competition was due to effort (often considered controllable) or chance (often considered uncontrollable), and heart rate, blood pressure, testosterone and cortisol levels were recorded. Those in the effort condition showed significantly higher testosterone levels, systolic and diastolic blood pressure values, and heart rate than those in the chance condition. The authors suggest that attributions to controllable factors are largely responsible for cardiovascular changes since they epitomize a challenge response associated with activation of the sympathetic adrenal medullary axis (SAM). Indeed, several investigations have shown that when people demonstrate a challenge response, SAM activation causes an increase in heart rate, dilation of arteries (lower total peripheral vascular resistance), and increased blood flow (higher cardiac output) (see Blascovich, 2008; Jones, Meijen, McCarthy, \& Sheffield, 2009).

Collectively, these findings suggest that controllability has an important role in hormonal and cardiovascular responses to competition. Specifically, they imply that a controllable attribution should lead to higher levels of testosterone, increases in blood pressure and heart rate, and lower levels of cortisol, than an uncontrollable attribution. These responses may occur because controllable attributions reflect a challenge response to social- 
evaluative threats (the challenge hypothesis; see Archer, 2006, 6.1-6.4). Accordingly, we might also expect other attribution dimensions to influence physiological processes provided they reflect a challenge response to competition outcomes. An attribution for failure deemed likely to change (over time and/or across situations and/or perceived as affecting all teams) and an attribution for success deemed likely to recur (over time and/or across situations and/or perceived as unique to the team) could also be considered a challenge response to competition and have additional effects on hormonal and cardiovascular responses of athletes. In regard to our model, we can predict that following team failure, perceptions of uncontrollability will result in lower levels of testosterone, decreases in blood pressure and heart rate, and higher levels of cortisol, particularly if the cause is also perceived to generalise across time and/or situations and/or perceived as unique to the team; following team success, perceiving the cause to generalise across time and/or situations and/or perceiving the cause as unique to the team will result in lower levels of cortisol, increases in heat rate and blood pressure, and higher levels of testosterone.

These effects are likely to be moderated by biological characteristics of athletes such as developmental level (age) and gender, upon which testosterone reactivity is heavily dependent (see Archer, 2006). In short, team attributions should have a meaningful effect on hormonal and cardiovascular responses of team members, and these responses are likely to impact both physical and mental well-being. Specifically, the likelihood of catching respiratory illnesses (e.g. colds and flu) increases because of changes in immune function caused by neuroendocrine activation (Jones \& Sheffield, 2007). These health changes will not only affect the quality and frequency of athlete training patterns but also impinge on the general well-being of athletes. Athlete well-being is an important consideration for sport practitioners and many consultants will look for interventions that can facilitate positive feeling states such as enjoyment, happiness, and excitement. Unfortunately there are 
relatively few sport specific models directed towards facilitating positive emotions in athletes (McCarthy, 2011). Here, we will outline how the attributions made for team outcomes can contribute to the emotional states of team members.

\section{Affective Consequences}

The attribution model of achievement motivation (Weiner, 1985, 2010; Weiner et al., 1971) has guided much of our understanding of how athletes respond emotionally to competition. This framework is an amalgamation and extension of Heider's (1958) theory of interpersonal relations and Rotter's (1966) theory of locus of control. It contends that attribution dimensions each have separate roles, but that controllability in particular (and the interaction of controllability and stability) is most important in observed relationships between attributions and discrete emotions - including pride, anger, pity, guilt, shame and gratitude (see Weiner, 1985). Much research in competitive sport has explored the relationship between attribution dimensions and emotional states of athletes (Allen, Jones, \& Sheffield, 2011b; Biddle et al., 2001; Graham, Kowalski, \& Crocker, 2002). However, despite the large body of evidence amassed, the link between attributions and emotions is far from compelling and no consistent patterns have emerged between discrete emotions and causal dimensions.

The inconsistent findings may be explained by considering the nature of competitive sport. Sport competitions are governed by match officials and have a set of specified rules that are generally absent from other achievement strivings. With such constraints on behaviour it is unlikely that emotions such as guilt, shame or pity will be experienced to any great extent. As a consequence, these emotions could be considered largely irrelevant to the attribution process in sport. The current framework excludes self-conscious emotions (e.g. embarrassment, shame, guilt) and focuses on six feeling states we believe will respond strongly to the attributions made by team members. These are: self-esteem, pride, anger, 
frustration, happiness and dejection. This does not necessarily mean that self-conscious emotions will not be experienced in sport. Simply that, in most cases, it is other defining features of competition (such as accidentally injuring an opponent - shame, or making an individual mistake - embarrassment), rather than the attributions made for team outcomes, that will largely determine these feeling states.

To date, most research on attributions in group settings has focused on associations with self-esteem (Hewstone, Rubin, \& Willis, 2002; Smurda et al., 2006). There is good support for a relationship between team attributions and self-esteem in team sport (Green \& Holman, 2004; Sherman \& Kim, 2005; Sherman, Kinias, Major, Kim, \& Prenovost, 2007) and several experimental studies have demonstrated that a greater use of team-serving attributions causes subsequent increases in social self-esteem (Smurda et al., 2006). A related emotion, pride, has also been assessed in attribution research (Tracy \& Robins, 2007; Nickel \& Spink, 2010). Both pride and self-esteem should respond similarly to attributions, and controllability in particular has been hypothesised have an important effect on these feeling states (Goetz, Frenzel, Stoeger, \& Hall, 2010). Further, the perceived mutability hypothesis (Roese \& Olson, 2007) points to an important role for the interaction of controllability and generalisability dimensions by describing how poor performance is less damaging to selfesteem when the circumstance is open to modification (e.g. controllable and unstable over time).

Alongside pride and self-esteem, team attributions should also influence feelings of anger and frustration. These two discrete but interlinked feeling states are commonly experienced following poor team performance (team defeat), and should demonstrate similar associations with team attributions. Most research in competitive sport has focused on feelings of anger and shown relatively inconsistent findings (Allen et al., 2009a; 2011b; Russell \& McAuley, 1986). Anger has been described as an attribution of blame (Weiner, 
1985) and should therefore occur when others are perceived as responsible for failure and also when people feel personally responsible for failure (self-blame). Moreover, anger and frustration should occur in response to perceptions of control (Weiner, 1985). In team settings, other-directed anger should surface in response to perceptions of uncontrollability whereas team-directed anger should surface in response to perceptions of team controllability. Further, the degree to which controllability affects anger is proposed to be moderated by the perceived stability of the cause (Weiner, 1985). We can hypothesise that other-directed anger will be more intense when perceptions of uncontrollability are perceived to generalise across time and/or situations and/or are perceived as unique to the team, whereas team-directed anger will be more intense when perceptions of controllability are perceived to generalise across time and/or situations and/or are perceived as unique to the team.

The degree to which people experience happiness following success, or dejection following failure, has also been linked to attributions in sport. Dejection (often labelled depression or sadness) has been positively associated with controllable attributions following poor performance (Robinson \& Howe, 1987) and happiness has been positively associated with controllable attributions following good performances (Allen et al., 2009b). More recently, the interaction of stability and controllability has been shown to have a strong effect on these two feeling states (Allen et al., 2011b). Specifically, golfers reported high levels of dejection (and low levels of happiness) when the cause of poor performance was perceived as personally controllable and stable, and reported low levels of dejection (and relatively high levels of happiness) when the cause of poor performance was perceived as personally controllable and unstable. Similar effects could be expected in group settings and we can hypothesise that interactions featuring controllability and other generalisability dimensions 
(globality and universality) will also be important for dejection and happiness in team sport. We now turn our attention to the cognitive responses of group members.

\section{Cognitive Consequences}

Team attributions have been proposed to have an important role in thought processes (Hewstone, 1989) and in particular attributions should have a strong effect on expectations (Weiner, 1985) and efficacy beliefs (Bandura, 1997). The importance of attributions for expectations and efficacy beliefs has been confirmed in several experimental studies (Le Foll, Rascle, \& Higgins, 2008; Orbach, Singer, \& Price, 1999; Rascle, Le Foll, \& Higgins, 2008) and applied practice (Greenlees, 2009; Parkes \& Mallett, 2011). Moreover, research probing the underlying attribution dimensions has shown important effects for causal stability and perceived controllability (Bond, Biddle, \& Ntoumanis, 2001; Gernigon \& Delloye, 2003). Like the relationship between attributions and emotions, self-efficacy theory also (nonexplicitly) points to an important role for the interaction of attribution dimensions: "the impact of effort attributions on efficacy beliefs will vary under different conceptions of ability and differing views of the controllability of effort" (Bandura, 1997, p.124). Recently, Rees and colleagues (Coffee \& Rees, 2008a, 2008b, 2009, 2011; Coffee, Rees, \& Haslam, 2009; Rees, 2007) have shown that, following success, efficacy beliefs increase when outcomes are attributed to causes that are perceived to generalise across time (stable) and/or situations (global) and/or are perceived as unique to the individual (personal); following failure, efficacy beliefs decrease when perceptions of uncontrollability are perceived to generalise across time and/or situations.

Because collective efficacy beliefs operate in similar ways to self-efficacy beliefs (Bandura, 1997) we can also expect the causes assigned to group outcomes to influence beliefs about team capability and expectations for future team success. Indeed, some initial research findings point to an important relationship between team attributions and collective 
efficacy (Allen et al., 2009b; Dithurbide et al., 2009; Greenlees, Filby, \& Wallis, 2003) with stability, controllability, and the interaction of these dimensions most commonly associated with changes in perceived collective efficacy from pre- to post-competition. In line with the research conducted by Rees and colleagues, we hypothesise that interactions featuring controllability and other generalisability dimensions (globality and universality) will also be important for collective efficacy and expectations for future team success.

Alongside expectations and efficacy beliefs, team attributions should also influence other thought processes including goals, intentions and decisions. Research exploring athletes' personal goals has demonstrated that attributing success to the self (typically a controllable attribution) is associated with upward goal revision (higher performance goals) whereas attributing failure to the self is associated with downward goal revision (lower performance goals) (Donovan \& Williams, 2003; Tolli \& Schmidt, 2008; Williams, Donovan, \& Dodge, 2000). We might expect similar effects to emerge in team sport with perceptions of team controllability, and interactions featuring controllability and generalisability dimensions, contributing to upward and downward goal revisions in team goals. Further, the decisions and intentions taken by team members are also hypothesised to change in response to attributions (Weiner, 1985). In some cases intentions will turn into actual behaviours and in other cases they will not. Because the same relationships should emerge regardless of whether researchers are focusing on behaviours or intentions/decisions to perform those behaviours, specific relationships are not outlined here but are detailed in the ensuing section.

\section{Behavioural Consequences}

So far we have discussed the mechanisms through which attributions can influence behaviour responses of group members (i.e. through the combined effects of affective, physiological, and cognitive responses to attribution) but have yet to discuss exactly how this 
might cause an increase or decrease in group productivity. Here we outline how the attributions made for group outcomes can influence the actions of group members and subsequent performance of sport teams.

Several experimental studies have demonstrated that sport performers tend to persist longer and put forth more effort when they attribute their unsuccessful performances to unstable and controllable causes than when they attribute their unsuccessful performances to stable and uncontrollable causes (Le Foll, Rascle, \& Higgins, 2006; Martinek \& Griffith, 1994; Ommundsen \& Vaglum, 1991; Orbach et al., 1999). These findings demonstrate the potential advantages of attribution retraining for positive behaviour development in athletes. However, we propose that such behaviour responses could be better described under a more generic response of approach and avoidance. That is, attributions to unstable and controllable factors are approach motivating because they provide greater opportunities for personal or team improvement and, in turn, encourage athletes to persist longer and put forth additional resources to achieve personal or group success.

Approach motivation is the energisation of behaviour by, or the direction of behaviour toward, positive stimuli (e.g. objects, events, goals), whereas avoidance motivation is the energisation of behaviour by, or the direction of behaviour away from, negative stimuli (Elliot, 2006). Research suggests that people automatically evaluate encounters on a positive-negative dimension (success or failure) and such evaluations automatically evoke approach and avoidance behaviour predispositions (see Elliott, 2006). Thus, it can be expected that the manner in which people explain such encounters also contribute to the energisation and direction of behaviour. We propose that following group success, approach motivation increases when attributions are perceived as stable over time and/or across situations and/or are perceived as unique to the team; following group failure, avoidance 
motivation increases when perceptions of uncontrollability are considered stable over time and/or across situations and/or are perceived as unique to the team.

Alongside effort and persistence, approach-avoidance actions could manifest in several other ways including dropout, coping strategies and goal choices. Specifically, team defeat attributed to avoidance motivating attributions (e.g. uncontrollable and stable) should predict greater instances of withdrawal from team, a greater use of avoidance coping strategies (behavioural or cognitive efforts to keep oneself from thinking about stressful situations) and a greater use of avoidance goals (performance goals grounded in the avoidance of failure). On the other hand, team defeat attributed to approach motivating attributions (e.g. controllable and unstable) should predict higher adherence levels, a greater use of problem-focused coping strategies (coping directed towards resolving the problem itself such as expending more effort or seeking support), and a greater use of approach goals (performance goals directed towards approaching a desirable outcome). These effects may also be observed through increases or decreases in task cohesion (a tendency for teams to remain united in pursuit of their instrumental objectives). Since high levels of task cohesion are central to goal directed behaviour (Carron, Hausenblas, \& Eys, 2005) we can expect approach motivating attributions to facilitate high levels of task cohesion. This has been observed in recent team attributional style research where, for unsuccessful team performances, a greater use of controllable, universal, unstable, and specific attributions was associated with greater task cohesion in team sport (Shapcott \& Carron, 2010).

Collectively, these behaviour responses should have a meaningful effect on the quality of training and subsequent performances of teams. Although the relationship between team attributions and future team performance remains relatively unexplored (Reimer, 2001; Wang, 1994) good support is available for a causal link between attributions and subsequent performances of individuals (Coffee \& Rees, 2011; Coffee et al., 2009; Martin-Krumm, 
Sarrazin, Peterson, \& Famose, 2003; Orbach, Singer, \& Murphey, 1997). In short, we expect approach motivating attributions to facilitate quality of training and subsequent team performance, and avoidance motivating attributions to debilitate quality of training and subsequent team performance. However, attributions are unlikely to have a strong direct effect on behaviour change (Weiner, 1985), but rather, a strong indirect effect through changes in cognitions, emotions, and neuroendocrine activation. Accordingly, we believe an important avenue for research inquiry is to identify salient mediators.

\section{Mediating Relationships}

Understanding the mechanisms through which attributions influence behaviour is an important endeavour for researchers. Our goal here is not to provide a detailed description of each of these relationships (as this can be inferred from Figure 1) but rather to illustrate the value of such research designs for evidence-based practice. Studies of individual sport performers have shown that self-efficacy mediates the relationship between attributions and behaviour intentions (Spink \& Nickel, 2009), attributions and performance goals (Tolli \& Schmidt, 2008), and attributions and future performance (Coffee \& Rees, 2011; Coffee et al., 2009). It would therefore seem reasonable that interventions targeting performance improvement should attempt to foster attributions that facilitate high levels of self-efficacy. In team settings, meta-analytic reviews have demonstrated that collective efficacy has a medium to strong effect on team performance (Gully, Incalcaterra, Joshi, \& Beaubien, 2002; Stajkovic, Lee, \& Nyberg, 2009) and therefore we might also expect team attributions to influence team performance through changes in collective efficacy. Activation and variation in testosterone levels have also been shown to predict decisions to compete again (Mehta \& Josephs, 2006), levels of cooperation (Mehta, Wuehrmann, \& Josephs, 2009) and approachavoidance behaviours (Mehta, Jones, \& Josephs, 2008). Accordingly, it would seem reasonable that the attributions made for team outcomes also contribute to these effects. 
One particularly useful approach to attribution research (and evidence-based practice) is to explore multiple mediators. Multiple mediator models are likely to provide more accurate assessments of mediation effects in many research contexts (MacKinnon, Fairchild, \& Fritz, 2007) and can help guide the development of attribution-based interventions by identifying salient mediators. For instance, team attributions are hypothesised to have a strong effect on both collective efficacy and emotions, but changes in team performance may occur through emotions only or through collective efficacy only. Relationships may become more complex as changes in hormones, emotions and cognitions feed back into attributions with reciprocating effects causing relationships to spiral and change with time. Longitudinal research designs can help shed further light on the specific nature of these effects.

\section{Measurement Issues}

In the opening pages of his seminal work the psychology of interpersonal relations, Heider (1958) commented on the interpersonal nature of attributions:

...in dealing with the person as a member of a dyad, he cannot be described as a lone subject in an impersonal environment, but must be represented as standing in relation to and interacting with another person. Moreover, the fact that the interrelation is with another person ... means that the psychological world of the other person as seen by the subject must enter into the analysis. Generally, a person reacts to what he thinks the other person is perceiving, feeling, and thinking, in addition to what the other person may be doing. (Heider, 1958, p. 1)

Throughout competitions team members observe the same external information and express their emotions, opinions and attitudes in the presence of their teammates. It is therefore unsurprising that some level of consensus is shown in the attributions made by team 
members (Shapcott, Carron, Greenlees, \& El Hakim, 2008). This clustering of data within teams has implications not only for the analyses used to test study hypotheses, but also for the types of questions that can be explored by researchers. In particular, researchers can explore a combination of both group means and variances. When variances are not equal across groups (i.e. the consensus on team attributions is greater in some groups than in others) it is possible to explore the structure of this effect on the variables of interest. Many statistical packages (e.g. Rasbash, Steele, Browne, \& Goldstein, 2009) allow researchers to simultaneously model means and variances providing the opportunity to ask different types of questions such as whether members of more experienced teams are in greater agreement about the causes of group outcomes (than are members of less experienced teams), or whether greater disagreement among team members (about the causes of group outcomes) influences team cohesion. Indeed, low levels of consensus on team attributions could be expected to decrease task cohesion since greater ambiguity could divide members on where to direct group resources. These types of research questions emerge naturally when probing multilevel data structures and may provide important insights into the attribution process operating in social structures.

One type of research design that we particularly encourage are those involving repeated measures. In team settings, athletes are continually receiving information that might alter initial perceptions of why their team performed above or below expectations. Thus, cross-sectional research designs may only provide partial information on how team attributions relate to the psychological and physiological states of team members. We encourage researchers to explore repeated measures data and studies in team settings will naturally foster a three-level data structure (i.e. repeated measures within individuals within teams). Three-level models are a straightforward extension of two-level models and can provide important information about the consistency of personal and team effects over time 
(Grimm \& Ram, 2012). Modelling variance may also be particularly important in repeated measures designs since the level of consensus in team member attributions is proposed to increase over time (Allen, 2010).

\section{Summary}

The attributions made for team outcomes are becoming an increasingly popular topic of inquiry. Like others, we believe that attributions are best understood when classified along dimensions that characterize their intrinsic meaning (e.g. stable or changing in time). The four dimensions proposed by Rees et al. (2005) have much potential for understanding attribution processes in group settings and the framework outlined here offers a foundation for several programmes of research directed towards understanding both the antecedents and consequences of attributions in team sport. In terms of formulating a research agenda, we recommend that researchers focus on three main issues: First, it is important to identify those factors (particular those that are easily modifiable) that contribute to the attributions made by team members. This is necessary if attribution retraining methods are to become more diverse and tailored towards specific populations of athletes. Second, it is important to confirm the hypothesised effect of team attributions on emotions, thought processes and neuroendocrine activation. In particular, researchers should begin to explore the main and interactive effects of attribution dimensions (for which it might be worthwhile modelling both means and variances) on those processes shown to have a strong effect on team performance. Finally, researchers should look to explore the interrelationships between these factors and behaviour responses including approach-avoidance actions, training patterns, and subsequent team performance. Multiple mediator models and longitudinal research designs would be particularly welcome in this respect. Research into these areas will provide sport psychology consultants with the information they need to deliver structured context-specific interventions that take into account all stages of the model. 
Currently, we know very little about the processes by which team attributions emerge, nor how such attributions affect responses of group members. Cross-sectional research designs have demonstrated some associations between two attribution dimensions (stability and controllability) and feelings of happiness, perceptions of collective efficacy and team cohesion, but further research, particularly those that address cause and effect, are necessary to help guide the development of appropriate interventions. Attribution retraining has become increasingly focused on controllability in recent years (e.g. Perry, Stupnisky, Hall, Chipperfield, \& Weiner, 2010) and we anticipate a greater focus on the interactive effects of attribution dimensions as researchers tailor their interventions towards a particular target (e.g. increasing collective efficacy). The delivery of attribution retraining in group settings provides additional challenges to practitioners in terms of engaging with each team member and we encourage future research to explore and identify the most effective methods of delivery.

This review is intended to provide a foundation on which future research can build. Our model explains many of the relationships already demonstrated in competitive sport and provides a number of new predictions awaiting confirmation. The model is firmly grounded in contemporary theory and research and is open to expansion into other related domains. Indeed, many of the relationships described here (particularly for hormonal and cardiovascular responses to competition) should hold true for self-referent attributions in addition to team-referent attributions. As research continues to accumulate and measurement tools become more refined we anticipate many future adjustments to this framework. We hope attribution research continues to flourish and provides greater opportunities for improving the training and performances of sport teams. 


\section{References}

Abramson, L. Y., Seligman, M. E. P., \& Teasdale, J. D. (1978). Learned helplessness in humans: Critique and reformulation. Journal of Abnormal Psychology, 87, 49-74.

Allen, M. S. (2009). Team attributions in sport. Journal of Sports Sciences, 27, S119-120.

Allen, M. S. (2010). On the temporal dynamics of causal attribution in competitive sport. International Review of Sport and Exercise Psychology, 3, 3-23.

Allen, M. S. (in press). A systematic review of content themes in sport attribution research: 1954 - 2011. International Journal of Sport and Exercise Psychology.

Allen, M. S., Greenlees, I., \& Jones, M. V. (2011a). An investigation of the five factor model of personality and coping behaviour in sport. Journal of Sports Sciences, 29, 841-850.

Allen, M. S., Jones, M. V., \& Sheffield, D. (2009a). Causal attribution and emotion in the days following competition. Journal of Sports Sciences, 27, 461-468.

Allen, M. S., Jones, M. V., \& Sheffield, D. (2009b). Attribution, emotion and collective efficacy in sport teams. Group Dynamics: Theory, Research, and Practice, 13, 205217.

Allen, M. S., Jones, M. V., \& Sheffield, D. (2010). The influence of positive reflection on attributions, emotions, and self-efficacy. The Sport Psychologist, 24, 211-226.

Allen, M. S., Jones, M. V., \& Sheffield, D. (2011b). Are the causes assigned to unsatisfactory performance related to the intensity of emotions experienced after competition? Sport and Exercise Psychology Review, 7(1), 3-10.

Anshel, M. H., \& Brinthaupt, T. M. (2006). Relationships between attributional style and trait anxiety for preadolescent Australian boys and girls. Australian Journal of Educational and Developmental Psychology, 6, 26-38.

Archer, J. (2006). Testosterone and human aggression: An evaluation of the challenge hypothesis. Neuroscience and Biobehavioral Reviews, 30, 319-345. 
Bandura, A. (1997). Self-efficacy: The exercise of control. New York, NY: Freeman.

Bateup, H. S., Booth, A., Shirtcliff, E. A., \& Granger, D. A. (2002). Testosterone, cortisol and women's competition. Evolution and Human Behavior, 23, 181-192.

Belciug, M. P. (1992). Effects of prior expectancy and performance outcome on attributions to stable factors in high performance competitive athletes. Journal for Research in Sport, Physical Education and Recreation, 14, 1-8.

Biddle, S. J. H., Hanrahan, S. J., \& Sellars, C. N. (2001). Attributions: Past, present, and future. In R. N. Singer, H. A. Hausenblas, \& C. M. Janelle (Eds.), Handbook of sport psychology (2 $2^{\text {nd }}$ ed., pp. 444-471). New York, NY: Wiley.

Bird, A. M., Foster, C. D., \& Maruyama, G. (1980). Convergent and incremental effects of cohesion on attributions for self and team. Journal of Sport Psychology, 2, 181-194.

Bird, A. M., \& Williams, J. M. (1980). A developmental-attributional analysis of sex-role stereotypes for sport performance. Developmental Psychology, 16, 319-322.

Blascovich, J. (2008). Challenge and threat. In A. J. Elliott (Ed.), Handbook of approach and avoidance motivation (pp. 431-445). New York, NY: Psychology Press.

Blascovich, J., Vanman, E. J., Mendes, W. B., \& Dickerson, S. (2011). Social psychophysiology for social and personality psychology. London, UK: Sage.

Bond, K. A., Biddle, S. J. H., \& Ntoumanis, N. (2001). Self-efficacy and causal attribution in female golfers. International Journal of Sport Psychology, 31, 243-256.

Carré, J. M., \& Putnam, S. K. (2010). Watching a previous victory produces an increase in testosterone among elite hockey players. Psychoneuroendocrinology, 35, 475-479.

Carron, A. V., Hausenblas, H. A., \& Eys, M. A. (2005). Group dynamics in sport ( $3^{\text {rd }}$ ed.). Morgantown, WV: Fitness Information Technology. 
Chow, G. M., \& Feltz, D. L. (2008). Exploring the relationships between collective efficacy, perceptions of success, and team attributions. Journal of Sports Sciences, 26, 11791189.

Coffee, P. (2010). Attributions: Contemporary research and future directions. Sport and Exercise Psychology Review, 6, 6-18.

Coffee, P., \& Rees, T. (2008a). The CSGU: A measure of controllability, stability, globality, and universality attributions. Journal of Sport and Exercise Psychology, 30, 611-641.

Coffee, P., \& Rees, T. (2008b). Main and interactive effects of controllability and generalisability attributions upon self-efficacy. Psychology of Sport and Exercise, 9, 775-785.

Coffee, P., \& Rees, T. (2009). The main and interactive effects of immediate and reflective attributions upon subsequent self-efficacy. European Journal of Sport Science, 9, 4152.

Coffee, P., \& Rees, T. (2011). When the chips are down: Effects of attributional feedback on self-efficacy and task performance following initial and repeated failure. Journal of Sports Sciences, 29, 235-245.

Coffee, P., Rees, T., \& Haslam, A. (2009). Bouncing back from failure: The interactive impact of perceived controllability and stability on self-efficacy beliefs and future task performance. Journal of Sports Sciences, 27, 1117-1124.

Croxton, J. S., Chiacchia, D., \& Wagner, C. (1987). Gender differences in attitudes towards sports and reactions to competitive situations. Journal of Sport Behavior, 10, 137-146.

Davis, H., \& Zaichkowsky, L. (1998). Explanatory style among elite ice hockey athletes. Perceptual and Motor Skills, 87, 1075-1080. 
Dickerson, S. S., \& Kemeny, M. E. (2004). Acute stressors and cortisol responses: A theoretical integration and synthesis of laboratory research. Psychological Bulletin, 130, 355-391.

Dithurbide, L., Sullivan, P., \& Chow, G. (2009). Examining the influence of team referent causal attributions and team performance on collective efficacy: A multilevel analysis. Small Group Research, 40, 491-507.

Donovan, J. J., \& Williams, K. J. (2003). Missing the mark: Effects of time and causal attributions on goal revision in response to goal-performance discrepancies. Journal of Applied Psychology, 88, 379-390.

Eagleton, J., McKelvie, S. J., \& deMan, A. (2007). Extraversion and neuroticism in team sport participants, individual sport participants, and nonparticipants. Perceptual and Motor Skills, 105, 265-266.

Elias, M. (1981). Serum cortisol, testosterone and testosterone-binding globulin responses to competitive fighting in human males. Aggressive Behavior, 7, 215-224.

Elliot, A. J. (2006). The hierarchical model of approach-avoidance motivation. Motivation and Emotion, 30, 111-116.

Försterling, F. (2001). Attribution: An introduction to theories, research and applications. Sussex, UK: Psychology Press.

Fry, A., Schilling, B., Fleck, S., \& Kraemer, W. (2011). Relationships between competitive wrestling success and neuroendocrine responses. Journal of Strength and Conditioning Research, 25, 40-45.

Gernigon, C. \& Delloye, J-B. (2003). Self-efficacy, causal attribution, and track athletic performance following unexpected success or failure among elite sprinters. The Sport Psychologist, 17, 55-76. 
Goetz, T., Frenzel, A. C., Stoeger, H., \& Hall, N. C. (2010). Antecedents of everyday positive emotions: An experience sampling analysis. Motivation and Emotion, 34, 49-62.

González-Bono, E., Salvador, A., Ricarte, J., Serrano, M. A., \& Arnedo, M. T. (2000). Testosterone and attribution of successful competition. Aggressive Behavior, 15, 409422.

González-Bono, E., Salvador, A., Serrano, M. A., \& Ricarte, J. (1999). Testosterone, cortisol and mood in sports team competition. Hormones and Behavior, 35, 55-62.

Gonzalez-Boto, R., Molinero, O., Martinez, R., \& Marquez, S. (2006). Attributions for success and failure in Spanish team sport players. European Journal of Human Movement, 17, 123-134.

Graham, T. R., Kowalski, K. C., \& Crocker, P. R. E. (2002). The contributions of goal characteristics and causal attributions to emotional experience in youth sport participants. Psychology of Sport and Exercise, 3, 273-291.

Green, T. D., \& Holeman, S. (2004). Athletes' attributions for team performance: A theoretical test across sports and genders. Social Behavior and Personality: an International Journal, 32, 199-206.

Greenlees, I. (2009). Enhancing confidence in a youth golfer. In B. Hemmings \& T. Holder (Eds.), Applied sport psychology: A case based approach (pp. 89-107). Chichester, UK: Wiley.

Greenlees, I., Filby, W. C. D., \& Wallis, J. (2003). Collective efficacy and team-referent attributions in male cricket players. In R. A. Stretch, T. D. Noakes, \& C. L. Vaughan (Eds.), A collection of papers from the Second World Congress of Science and Medicine in Cricket (pp. 179-181). Port Elizabeth, South Africa: University of Port Elizabeth. 
Greenlees, I., Graydon, J. K., \& Maynard, I. W. (2000). The impact of collective efficacy beliefs on team-referent attributions. Journal of Sports Sciences, 17, S49.

Greenlees, I., Jones, S., Holder, T., \& Thelwell, R. (2006). The effects of self-handicapping on attributions and perceived judo competence. Journal of Sports Sciences, 24, 273280.

Greenlees, I., Lane, A. M., Thelwell, R., Holder, T., \& Hobson, G. (2005). Team-referent attributions among sport performers. Research Quarterly for Exercise and Sport, 76, 477-487.

Greenlees, I., Stopforth, M., Graydon, J., Thelwell, R., Filby, W., \& El-Hakim, Y. (2007). The impact of match importance and gender on the team-serving attributional bias among interdependent sports team players. Group Dynamics: Theory, Research, and Practice, 11, 54-65.

Grimm, K. J., \& Ram, N. (2012). Modeling change over time. In G. Tenenbaum, R. Eklund, \& A. Kamata (Eds.), Handbook of measurement in sport and exercise psychology. Champaign, IL: Human Kinetics.

Grove, J. R., \& Prapavessis, H. (1995). The effect of skill level and sport outcomes on dimensional aspects of causal attributions. Australian Psychologist, 30, 92-95.

Gully, S. M., Incalcaterra, K. A., Joshi, A., \& Beaubien, J. M. (2002). A meta-analysis of team-efficacy, potency, and performance: Interdependence and level of analysis as moderators of observed relationships. Journal of Applied Psychology, 87, 819-832.

Hamilton, P. R., \& Jordan, J. S. (2000). Most successful and least successful performances: Perceptions of causal attributions in high school track athletes. Journal of Sport Behavior, 23, 245-254. 
Hanrahan, S. J., \& Cerin, E. (2009). Gender, level of participation, and type of sport: Differences in achievement goal orientation and attributional style. Journal of Science and Medicine in Sport, 12, 508-512.

Heider, F. (1958). The psychology of interpersonal relations. New York, NY: Wiley.

Hendy, H. M., \& Boyer, B. J. (1993). Gender differences in attributions for triathlon performance. Sex Roles, 29, 527-543.

Hewstone, M. (1989). Causal attribution: From cognitive processes to collective beliefs. Oxford, UK: Basil Blackwell.

Hewstone, M., Rubin, M., \& Willis, H. (2002). Intergroup bias. Annual Review of Psychology, 53, 575-604.

Hull, J. G., van Treuren, R. R., \& Propsom, P. M. (1988). Attributional style and the components of hardiness. Personality and Social Psychology Bulletin, 14, 505-513.

Jones, E. E., \& Davis, K. E. (1965). From acts to dispositions: The attribution process in person perception. In L. Berkowitz (Ed.), Advances in experimental social psychology (Vol. 2., pp. 219-266). New York, NY: Academic Press.

Jones, M. V., Meijen, C., McCarthy, P. J., \& Sheffield, D. (2009). A theory of challenge and threat states in athletes. International Review of Sport and Exercise Psychology, 2, 161-180.

Jones, M. V., \& Sheffield, D. (2007). The impact of game outcome on the well-being of athletes. International Journal of Sport and Exercise Psychology, 5, 54-65.

Kelley, H. H. (1967). Attribution theory in social psychology. In D. Levine (Ed.), Nebraska symposium on motivation (Vol. 15., pp. 192-240). Lincoln, NE: University of Nebraska Press.

Kerr, R. H., \& Beh, H. C. (1995). Attributions of causality in different grades of Australian football league players. Australian Psychologist, 30, 102-108. 
Lau, R. R. (1984). Dynamics of the attribution process. Journal of Personality and Social Psychology, 46, 1017-1028.

Lau, R. R., \& Russell, D. (1980). Attributions in the sports pages. Journal of Personality and Social Psychology, 39, 29-38.

Le Foll, D., Rascle, O., \& Higgins, N. C. (2006). Persistence in a putting task during perceived failure: Influence of state-attributions and attributional style. Applied Psychology: An International Review, 55, 586-605.

Le Foll, D., Rascle, O., \& Higgins, N. C. (2008). Attributional feedback-induced changes in functional and dysfunctional attributions, expectations of success, hopefulness, and short-term persistence in a novel sport. Psychology of Sport and Exercise, 9, 77-101.

MacKinnon, D. P., Fairchild, A. J., \& Fritz, M. S. (2007). Mediation analysis. Annual Review of Psychology, 58, 593-614.

Malle, B. F. (2004). How the mind explains behavior: Folk explanations, meaning, and social interaction. Cambridge, MA: MIT Press.

Martin-Krumm, C. P., Sarrazin, P. G., Peterson, C., \& Famose, J-P. (2003). Explanatory style and resilience after sports failure. Personality and Individual Differences, 35, 16851695.

Martinek, T. J., \& Griffith, J. B. (1994). Learned helplessness in physical education: A developmental study of causal attributions and task persistence. Journal of Teaching in Physical Education, 13, 382-393.

Mazur, A., \& Lamb, T. A. (1980). Testosterone, status, and mood in human males. Hormones and Behavior, 14, 236-246.

McCarthy, P. J. (2011). Positive emotion in sport performance: Current status and future directions. International Review of Sport and Exercise Psychology, 4, 50-69. 
Mehta, P. H., Jones, A. C., \& Josephs, R. A. (2008). The social endocrinology of dominance: Basal testosterone predicts cortisol changes and behavior following victory and defeat. Journal of Personality and Social Psychology, 94, 1078-1093.

Mehta, P. H., \& Josephs, R. A. (2006). Testosterone changes after losing predicts the decision to compete again. Hormones and Behavior, 50, 684-692.

Mehta, P. H., Wuehrmann, E. V., \& Josephs, R. A. (2009). When are low testosterone levels advantageous? The moderating role of individual versus intergroup competition. Hormones and Behavior, 56, 158-162.

Mezulis, A. H., Abramson, L. Y., Hyde, J. S., \& Hankin, B. L. (2004). Is there a universal positivity bias in attributions? A meta-analytic review of individual, developmental, and cultural differences in the self-serving attributional bias. Psychological Bulletin, $130,711-747$.

Moscovici, S. \& Hewstone, M. (1983). Social representations and explanations: From the 'naïve' to the 'amateur' scientist. In M. Hewstone (Ed.), Attribution theory: Social and functional extensions (pp. 48-125). Oxford, UK: Blackwell.

Myers, N. D., \& Feltz, D. L. (2007). From self-efficacy to collective efficacy in sport: Transitional methodological issues. In G. Tenenbaum, \& R. C. Eklund (Eds.), Handbook of sport psychology ( $3^{\text {rd }}$ ed., pp 799-819). New York, NY: Wiley.

Nickel, D., \& Spink, K. S. (2010). Attributions for health-related physical activity. Journal of Applied Social Psychology, 40, 2927-2945.

Oliveira, T., Gouveia, M. J., \& Oliveira, R. F. (2009). Testosterone responsiveness to winning and losing experiences in female soccer players. Psychoneuroendocrinology, 34, 1056-1064. 
Ommundsen, Y., \& Vaglum, P. (1991). The influence of attributional style on the soccerrelated self-esteem and persistence in soccer of young boys. Scandinavian Journal of Medicine and Science in Sports, 1, 45-50.

Orbach, I., Singer, R. N., \& Murphey, M. (1997). Changing attributions with an attribution training technique related to basketball dribbling. The Sport Psychologist, 11, 294304.

Orbach, I., Singer, R. N., \& Price, S. (1999). An attribution training program and achievement in sport. The Sport Psychologist, 13, 69-82.

Parkes, J. F., \& Mallett, C. J. (2011). Developing mental toughness: Attributional style retraining in rugby. The Sport Psychologist, 25, 269-287.

Passelergue, P., \& Lac, G. (1999). Saliva cortisol, testosterone and T/C ratio variations during a wrestling competition and during the postcompetitive recovery period. International Journal of Sports Medicine, 20, 109-113.

Pederson, D. M., \& Manning, C. L. (2004). Attributions of athletes on collegiate sports teams. Perceptual and Motor Skills, 99, 799-810.

Perry, R. P., Stupnisky, R. H., Hall, N. C., Chipperfield, J. G., \& Weiner, B. (2010). Bad starts and better finishes: Attributional retraining and initial performance in competitive achievement settings. Journal of Social and Clinical Psychology, 29, 668-700.

Prapavessis, H., \& Carron, A. V. (1988). Learned helplessness in sport. The Sport Psychologist, 2, 189-201.

Rasbash, J., Steele, F., Browne, W. J., \& Goldstein, H. (2009). A user's guide to MLwiN: Version 2.10. Bristol, UK: Centre for Multilevel Modelling, University of Bristol. Rascle, O., Le Foll, D., \& Higgins, N. C. (2008). Attribution retraining alters novice golfers' free practice behavior. Journal of Applied Sport Psychology, 20, 157-164. 
Rees, T. (2007). Main and interactive effects of attribution dimensions on efficacy expectations in sport. Journal of Sports Sciences, 25, 473-480.

Rees, T., Ingledew, D. K., \& Hardy, L. (2005). Attribution in sport psychology: Seeking congruence between theory, research and practice. Psychology of Sport and Exercise, 6, 189-204.

Reimer, T. (2001). Attributions for poor group performance as a predictor of perspectivetaking and subsequent group achievement: A process model. Group Processes and Intergroup Relations, 4, 31-47.

Rhea, D. J., \& Martin, S. (2010). Personality trait differences of traditional sport athletes, bullriders, and other alternative sport athletes. International Journal of Sports Science and Coaching, 5, 75-85.

Ricarte, J., Salvador, A., Costa, R., Torres, M. J., \& Subirats, M. (2001). Heart rate and blood pressure responses to a competitive role-playing game. Aggressive Behavior, 27, 351359.

Robinson, D. W., \& Howe, B. L. (1987). Causal attribution and mood state relationships of soccer players in a sport achievement setting. Journal of Sport Behavior, 10, 137-146.

Roesch, S. C., \& Amirkhan, J. H. (1997). Boundary conditions for self-serving attributions: Another look at the sports pages. Journal of Applied Social Psychology, 27, 245-261.

Roese, N. J., \& Olson, J. M. (2007). Better, stronger, faster: Self-serving judgement, affect regulation, and the optimal vigilance hypothesis. Perspectives on Psychological Science, 2, 124-141.

Rotter, J. B. (1966). Generalised expectancies for internal versus external control of reinforcement. Psychological Monographs, 80, 1-28. 
Russell, D., \& McAuley, E. (1986). Causal attributions, causal dimensions, and affective reactions to success and failure. Journal of Personality and Social Psychology, 50, 1174-1185.

Salvador, A. (2005). Coping with competitive situations in humans. Neuroscience and Biobehavioral Reviews, 29, 195-205.

Salvador, A., \& Costa, R. (2009). Coping with competition: Neuroendocrine responses and cognitive variables. Neuroscience and Biobehavioral Reviews, 33, 160-170.

Schmitt, D. P., Realo, A., Voracek, M., \& Allik, J. (2008). Why can't a man be more like a woman? Sex differences in big five personality traits across 55 cultures. Journal of Personality and Social Psychology, 94, 168-182.

Serrano, M. A., Salvador, A., González-Bono, E., Sanchis, C., \& Suay, F. (2000). Hormonal responses to competition. Psicothema, 12, 440-444.

Shapcott, K. M., \& Carron, A. V. (2010). Development and validation of a team attributional style questionnaire. Group Dynamics: Theory, Research, and Practice, 14, 93-113.

Shapcott, K. M., Carron, A. V., Greenlees, I., \& El Hakim, Y. (2008). Do member attributions for team outcomes represent a collective belief? Psychology of Sport and Exercise, 9, 487-492.

Shapcott, K. M., Carron, A. V., Greenlees, I., \& El Hakim, Y. (2010). Determinants of teamreferent attributions: A multi-level analysis. International Journal of Sport and Exercise Psychology, 8, 227-244.

Sherman, D. K., \& Kim, H. S. (2005). Is there an "I" in "team"? The role of the self in groupserving judgments. Journal of Personality and Social Psychology, 88, 108-120.

Sherman, D. K., Kinias, Z., Major, B., Kim, H. S., \& Prenovost, M. (2007). The group as a resource: Reducing biased attributions for group success and failure via group affirmation. Personality and Social Psychology Bulletin, 33, 1100-1112. 
Smurda, J. D., Wittig, M. A., \& Gokalp, G. (2006). Effects of threat to a valued social identity on implicit self-esteem and discrimination. Group Processes and Intergroup Relations, 9, 181-197.

Spink, K. S., \& Nickel, D. (2009). Self-regulatory efficacy as a mediator between attributions and intention for health-related physical activity. Journal of Health Psychology, 15, $75-84$.

Stajkovic, A. D., Lee, D., \& Nyberg, A. J. (2009). Collective efficacy, group potency, and group performance: Meta-analyses of their relationships, and test of a mediation model. Journal of Applied Psychology, 94, 814-828.

Stoeber, J., \& Becker, C. (2008). Perfectionism, achievement motives, and attribution of success and failure in female soccer players. International Journal of Psychology, 43, 980-987.

Suay, F., Salvador, A., González-Bono, E., Sanchis, C., Martinez, M., ... Montoro, J. B. (1999). Effects of competition and its outcome on serum testosterone, cortisol and prolactin. Psychoneuroendocrinology, 24, 551-566.

Tajfel, H., \& Turner, J. C. (1986). The social identity theory of intergroup behavior. In S. Worchel and L. W. Austin (Eds.), Psychology of intergroup relations. Chicago, IL: Nelson-Hall.

Taylor, D. M., Doria, J. R., \& Tyler, J. K. (1983). Group performance and cohesiveness: An attribution analysis. Journal of Social Psychology, 119, 187-198.

Taylor, D. M., \& Tyler, J. (1986). Group members' responses to group-serving attributions for success and failure. Journal of Social Psychology, 126, 775-781.

Tolli, A. P., \& Schmidt, A. M. (2008). The role of feedback, causal attributions, and selfefficacy in goal revision. Journal of Applied Psychology, 93, 692-701. 
Tracy, J. L., \& Robins, R. W. (2007). The psychological structure of pride: A tale of two facets. Journal of Personality and Social Psychology, 92, 506-525.

Van Anders, S. M., \& Watson, N. V. (2007). Effects of ability- and chance-determined competition outcome on testosterone. Physiology and Behavior, 90, 634-642.

van der Meij, L., Buunk, A. P., Almela, M., \& Salvador, A. (2010). Testosterone responses to competition: The opponent's psychological state makes it challenging. Biological Psychology, 84, 330-335.

Wang, Z. M. (1994). Group attributional training as an effective approach to human resource development under team work systems. Ergonomics, 37, 1137-1144.

Weiner, B. (1985). An attributional theory of achievement motivation and emotion. Psychological Review, 92, 548-573.

Weiner, B. (2010). The development of an attribution-based theory of motivation: A history of ideas. Educational Psychologist, 45, 28-36.

Weiner, B., Frieze, I.H., Kukla, A., Reed, L., Rest, S., \& Rosenbaum, R.M. (1971). Perceiving the causes of success and failure. In E. E. Jones, D. E. Kanouse, H. H. Kelley, R. E. Nisbett, S. Valins, \& B. Weiner (Eds.), Attribution: Perceiving the causes of behaviour (pp. 95-120). Morristown, NJ: General Learning Press.

White, S. A. (1993). The effect of gender and age on causal attribution in softball players. International Journal of Sport Psychology, 24, 49-58.

Williams, K. J., Donovan, J. J., \& Dodge, T. L. (2000). Self-regulation of performance: Goal establishment and goal revision processes in athletes. Human Performance, 13, 159180.

Zaccaro, S. J., Peterson, C., \& Walker, S. (1987). Self-serving attributions for individual and group performance. Social Psychology Quarterly, 50, 257-263. 
Figure 1: A framework for investigating team attributions in sport

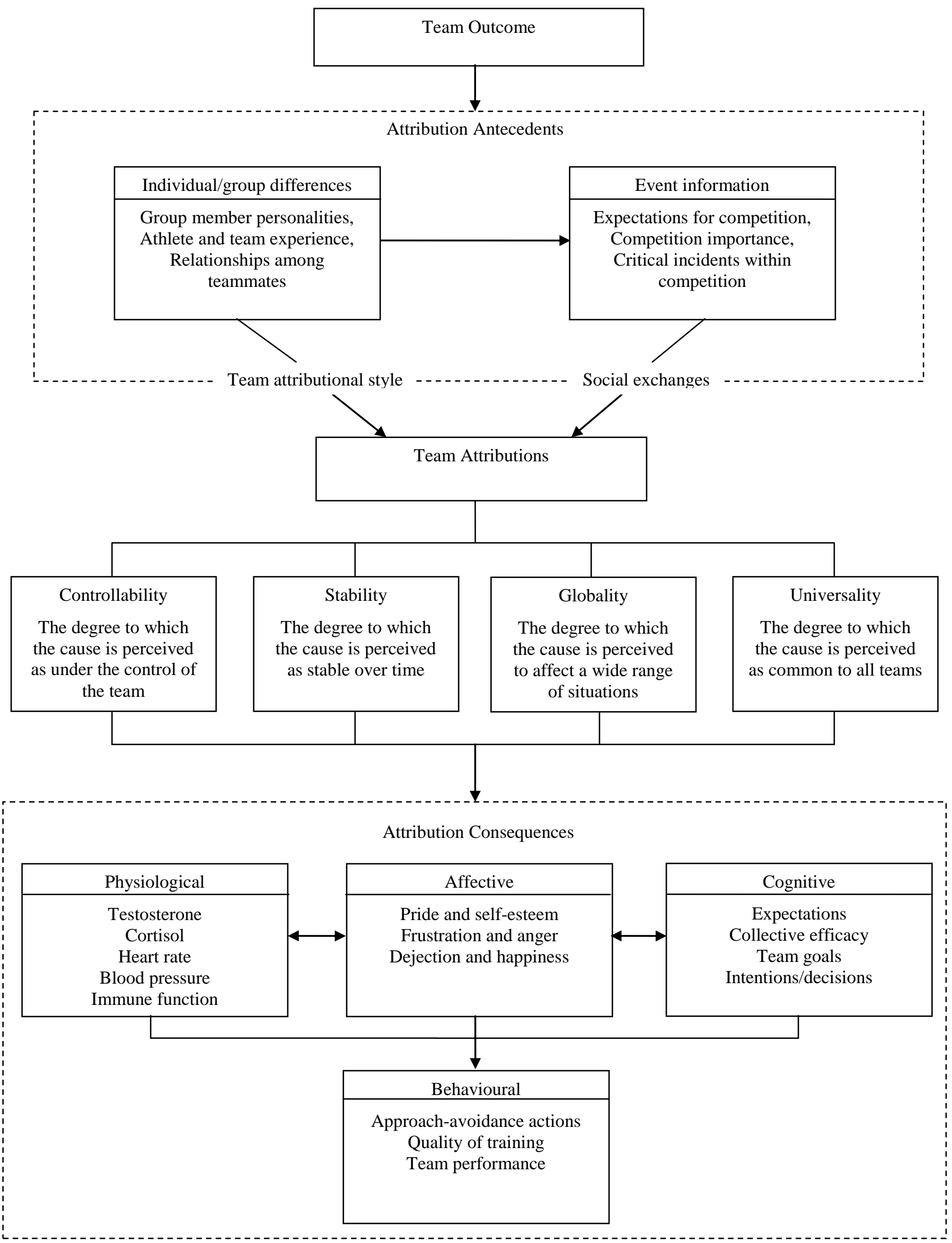

